\title{
Low iodine diet does not improve the efficacy of radioiodine for the treatment of Graves' disease
}

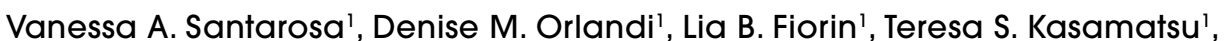
Gilberto K. Furuzawa', Ilda S. Kunii', Rosália P. Padovani ${ }^{1,2}$, Marília M. S. Marone², Mário L. Castiglioni' ${ }^{3}$, José Gilberto H. Vieira', Rui M. B. Maciel', Magnus R. Dias-da-Silva', João R. M. Martins'

\begin{abstract}
Objective: Consuming a low-iodine diet (LID) is a widely accepted practice before administering radioiodine $\left({ }^{131}\right.$ I) to evaluate and to treat thyroid disease. Although this procedure is well established for the management of patients with differentiated thyroid cancer, its use in patients with benign disease is unclear. So, we aimed to evaluate the influence of a LID on the outcome in patients with Graves' disease (GD) treated with ${ }^{131}$ l. Subjects and methods: We evaluated 67 patients with GD who were divided into 2 groups: one group $(n=31)$ consumed a LID for 1-2 weeks, and the second group ( $n=36$ ) was instructed to maintain a regular diet (RD). Results: The LID group experienced a $23 \%$ decrease in urinary iodine after 1 week on the diet and a significant $42 \%$ decrease after 2 weeks on the diet. The majority (53\%) of the patients in the LID group had urinary iodine levels that were consistent with deficient iodine intake. However, there was no difference in the rate of hyperthyroidism's cure between the LID and the RD groups 6 months after ${ }^{131}$ I therapy. Furthermore, the therapeutic efficacy did not differ in patients with varying degrees of sufficient iodine intake (corresponding urinary iodine levels: $<10 \mu \mathrm{g} / \mathrm{dL}$ is deficient; $10-29.9 \mu \mathrm{g} / \mathrm{dL}$ is sufficient; and $>30 \mu \mathrm{g} / \mathrm{dL}$ is excessive). Conclusion: In the present study, we demonstrated that although a LID decreased urinary iodine levels, those levels corresponding with sufficient or a mild excess in iodine intake did not compromise the therapeutic efficacy of ${ }^{131}$ I for the treatment of GD. Arch Endocrinol Metab. 2015;59(6):501-6
\end{abstract}

Keywords

Urinary iodine; iodine nutritional status; radioiodine; Graves' disease
1 Laboratório de Endocrinologia

Molecular e Translacional, Divisão de Endocrinologia, Departamento de

Medicina, Escola Paulista de Medicina, Universidade Federal de São Paulo (EPM-Unifesp), São Paulo, SP, Brasil 2 Departamento de Medicina Nuclear, Irmandade Santa Casa de Misericórdia de São Paulo (ISCMSP), São Paulo, SP, Brasil ${ }^{3}$ Divisão de Medicina Nuclear,

Departamento de Diagnóstico por Imagem, EPM-Unifesp,

São Paulo, SP, Brasil

Vanessa A. Santarosa and Denise M. Orlandi contributed equally to this work

Correspondence to:

João R. M. Martins

Laboratório de Endocrinologia

Molecular e Translacional,

Divisão de Endocrinologia,

Departamento de Medicina,

Escola Paulista de Medicina,

Universidade Federal de São Paulo

Rua Pedro de Toledo, 669, $11^{\circ}$ andar

04039-032 - São Paulo, SP, Brazil

jrmmartins.bioq@epm.br

Received on May/5/2015

Accepted on Jun/18/2015

DOI: 10.1590/2359-3997000000082

\section{INTRODUCTION}

$\mathrm{R}$ adioiodine $\left({ }^{131} \mathrm{I}\right)$ represents one of the first-line therapies for Graves' disease (GD) (1-4). In the majority of cases, a single dose of ${ }^{131} \mathrm{I}$ is sufficient to restore the patient to euthyroidism or hypothyroidism within 6 to 12 months (4). Despite its efficacy, radioiodine therapy (RAIT) fails in $10-50 \%$ of cases (4). The success of RAIT is influenced by many variables, including gender, age, thyroid volume, prior use of antithyroid drugs and baseline free thyroxine (FT4) levels; however, none of these variables reliably predict the outcome after RAIT (5-12).

The effect of RAIT is directly correlated to the dose of ${ }^{131} \mathrm{I}$ as well as to the dose absorbed by the thyroid tissue (12) although one study showed no difference in this respect (13). It is known that thyroid uptake varies based on the availability of dietary iodine. A decline in radioiodine uptake has been observed over time in populations with benign thyroid disease who are exposed to high amounts of iodine in accordance with public policies of iodine supplementation $(14,15)$. Moreover, previous studies have reported that a $25 \%$ decline in iodine uptake occurs when iodine excretion is increased by 2 -fold $(12,16)$.

To increase ${ }^{131} \mathrm{I}$ uptake, a stringent low-iodine diet (LID) is recommended and its efficacy is easily monitored by measuring urinary iodine levels $(17,18)$. A LID reduces plasma iodine levels, leading to increased expression of sodium-iodide symporter (NIS), thereby increasing ${ }^{131}$ I uptake $(19,20)$. Although this practice has been widely accepted for the management of differentiated thyroid cancer (DTC), its use in evaluating and treating benign thyroid diseases, particularly GD, has not been demonstrated. In fact, recent guidelines and reviews have suggested that high plasma iodine levels rarely compromise RAIT for thyrotoxicosis and that a LID is only indicated in cases of DTC or nontoxic goiters $(1,3,12)$. However, information regarding the effects of LID on the therapeutic efficacy of ${ }^{131} \mathrm{I}$ on GD is lacking. 
In the present study, we aimed to evaluate the effectiveness of a LID at achieving a nutritionally deficient state and to determine the impact of this condition on the response to ${ }^{131}$ I treatment.

\section{SUBJECTS AND METHODS}

\section{Patients}

We enrolled consecutively 67 patients with GD (59 women and 8 men; age range, 16-76 years) who were referred to our Thyroid Outpatient Clinic. GD was diagnosed based on the presence of signs and symptoms of hyperthyroidism, diffuse goiter and laboratory tests consistent with thyrotoxicosis. The Ethical Committee of our institution approved the protocol (CAAE: 02584112.5.0000.5505) and all the patients signed an informed consent.

\section{Laboratory analyses}

Patients were followed for 2 weeks before RAIT and were examined weekly to determine thyroid function and to measure urinary iodine levels. Serum free thyroxine (FT4) and thyroid-stimulating hormone (TSH) levels were determined by electrochemiluminescence using commercially available kits (Roche Diagnostics, Mannheim, Germany). The reference values were as follows: $\mathrm{TSH}=0.3-4.0 \mathrm{mU} / \mathrm{L}$ and FT4 $=0.6-1.5 \mathrm{ng} / \mathrm{dL}$. Thyroid ultrasound was performed in all patients using an ENVISOR Doppler Duplex (Philips, Andover, MA, USA), with a $12-\mathrm{MHz}$ linear array transducer. The same examiner, who was blinded to the patients' clinical conditions, performed all of the thyroid measurements.

Urinary iodine from spot samples was quantified by a semi-automatic spectrophotometric method using the Sandell-Kolthoff reaction (21). Each sample was digested with $0.1 \mathrm{M}$ ammonium persulfate for $60 \mathrm{~min}$ utes at $95^{\circ} \mathrm{C}$. After cooling, the samples were incubated with $0.02 \mathrm{M}$ arsenious acid for 15 minutes and with $0.02 \mathrm{M}$ ceric sulfate for 40 minutes, and the absorbance was measured at $405 \mathrm{~nm}$. The amount of iodine present in each sample was determined by comparing the absorbance with a standard curve. This technique has an analytical sensitivity of $1.0 \mu \mathrm{g} / \mathrm{dL}$.

\section{Low-iodine diet}

Two weeks before RAIT, the patients were allocated alternately into 2 groups: one group consumed a LID $(\mathrm{n}=31)$, corresponding to a maximum amount of 50 $\mu \mathrm{g}$ iodine/day (22), and the other group $(\mathrm{n}=36)$ was instructed to maintain a regular diet $(\mathrm{RD})$. We monitored patient compliance to their diet each week and emphasized its importance. Considering that a restrictive diet would result in urinary iodine excretion levels consistent with iodine nutritional deficiency, dietary efficacy was also interpreted based on the iodine nutritional status criteria developed by the International Council for Control of Iodine Deficiency Disorders (ICCIDD) and the World Health Organization (WHO). Urinary iodine excretion < $10 \mu \mathrm{g} / \mathrm{dL}$ indicates deficient intake; urinary iodine between $10 \mu \mathrm{g} / \mathrm{dL}$ and $29.9 \mu \mathrm{g} / \mathrm{dL}$ denotes a sufficient nutritional status; and urinary iodine $\geq 30 \mu \mathrm{g} / \mathrm{dL}$ corresponds to excessive iodine ingestion.

\section{Radioiodine therapy and follow-up}

All of the patients discontinued antithyroid drugs 5 days before RAIT. All patients received a fixed dose of $555 \mathrm{MBq}(15 \mathrm{mCi})$ of ${ }^{131} \mathrm{I}$. Antithyroid medication was reintroduced in the follow up to the symptomatic patients with persistent low TSH and increased FT4.

After treatment, the patients were examined at 1, 2, 3 and 6 months for clinical and laboratory evaluations. At 6 months of follow-up, patients were classified as "cured" if: a) they developed hypothyroidism and were receiving levothyroxine (LT4) replacement; or b) the FT4 levels were within the reference range with no use of antithyroid medication.

\section{Statistical analysis}

We utilized the Mann-Whitney test to compare the quantitative variables (age, TSH levels, T4L levels, urinary iodine concentration and thyroid volume). We analyzed gender and treatment response using Fisher's exact test. We utilized ANOVA to compare the temporal progression of urinary iodine levels from baseline to 1 week to 2 weeks on a LID. Statistical significance was established at $\mathrm{p}<$ 0.05 . We performed all of the analyses using GraphPad Prism 5.0 (GraphPad Software, Inc., La Jolla, CA, USA).

\section{RESULTS}

\section{The impact of a LID on urinary iodine excretion}

Table 1 presents the clinical and laboratory characteristics of the patients included in the study. At baseline, there were no significant differences between the LID and the $\mathrm{RD}$ groups in terms of gender, age, duration of disease, thyroid volume or TSH, FT4 or urinary iodine levels. 
Table 1. Clinical and laboratory characteristics of patients who were maintained on low-iodine diet (LID) or in regular diet (RD)

\begin{tabular}{lccc}
\hline Parameters & LID $(\mathbf{N}=\mathbf{3 1})$ & RD $(\mathbf{N}=\mathbf{3 6})$ & $\mathbf{P}$ \\
\hline Gender (F:M) & $28: 3$ & $31: 5$ & 0.71 \\
Age (years) & $45(23-72)$ & $43(16-76)$ & 0.86 \\
Duration of GD (years) & $3.0(1.0-15)$ & $2.0(1.0-15)$ & 0.17 \\
TSH (mU/L) & $0.05(0.05-10.1)$ & $0.35(0.05-20.6)$ & 0.18 \\
T4L (ng/dL) & $1.3(0.5-6.0)$ & $1.3(0.4-6.0)$ & 0.79 \\
Initial urinary iodine $(\mu \mathrm{gg} / \mathrm{dL})$ & $20.1(4.9-45)$ & $22.1(4.0-68.7)$ & 0.36 \\
Thyroid volume $(\mathrm{mL})$ & $40(8.3-189)$ & $25.1(8.3-62)$ & 0.06 \\
\hline
\end{tabular}

Values represent the median and minimum-maximum values between parentheses. LID: Iowiodine diet; RD: regular diet; F: female; M: male; GD: Graves's disease.

After a restrictive diet, the urinary iodine levels in the LID group decreased by $23 \%$ after the first week ( $\mathrm{p}$ $=0.054$ ) followed by a significant $42 \%$ decline after 2 weeks (Figure 1A). However, there was no significant difference in the reduction in urinary iodine levels between 1 week and 2 weeks on a LID. In the RD group, there was no difference in urinary iodine excretion after 1 or 2 weeks compared with baseline (Figure 1B).

The proportion of patients in the LID and RD groups whose iodine urinary excretion indicated deficient, sufficient or excessive iodine intake did not differ at baseline (Table 2); nevertheless, more than $80 \%$ of the patients in both groups presented with urinary iodine levels compatible with sufficient or excessive iodine intake. However, in the LID group, the proportion of patients who exhibited levels consistent with deficient iodine intake after 2 weeks on the restrictive diet increased from $16 \%$ to more than $53 \%(\mathrm{p}<0.05)$. Further, the percentage of patients with urinary iodine levels corresponding to excessive iodine intake decreased significantly from $26 \%$ to less than $7 \%$. Nevertheless, approximately $40 \%$ of the patients who consumed a LID had urinary iodine levels that were compatible with sufficient or excessive iodine intake. In the $\mathrm{RD}$ group, the percentage of patients with urinary iodine levels corresponding to deficient iodine intake increased from $8.3 \%$ to $30.5 \%$. However, in this group, those patients with urinary iodine levels indicative of sufficient or excessive iodine intake remained nearly constant throughout the study (Table 2).

\section{The impact of LID on the response to radioiodine}

Patients who progressed to hypothyroidism or maintained their FT4 levels within the reference values were considered to be cured. We compared the proportion of cured patients in the LID and the RD groups and did not identify a statistical difference between them during the follow-up period (Table 3 ). In the low iodine $\operatorname{diet}(\mathrm{LID})$ group, there were $0,7,17$ and 21 patients in hypothyroidism at $1^{\text {th }}, 2^{\text {nd }}, 3^{\text {rd }}$ and $6^{\text {th }}$ months after ${ }^{131}$ I, respectively; while $9,11,7$ and 5 patients were in euthyroidism at the same period of times. On the other hand, in the regular diet (RD) group, there were 0,9 , 21 and 23 patients in hypothyroidism at $\mathrm{l}^{\text {th }}, 2^{\text {nd }}, 3^{\text {rd }}$ and

Table 2. Distribution of patients according to the adequacy of iodine intake as recommended by ICCIDD/WHO

\begin{tabular}{lccc}
\hline & \multicolumn{3}{c}{ Number of patients (\%) } \\
\cline { 2 - 4 } & Deficiency & Sufficiency & Excessive \\
\hline LID & & & \\
Baseline & $5(16.7)$ & $17(57.7)$ & $8(26.6)$ \\
1 week & $9(30)^{\star}$ & $18(60)$ & $3(10)$ \\
2 weeks & $16(53.3)^{\star}$ & $12(40)$ & $2(6.7)$ \\
RD & & & \\
Baseline & $3(8.3)$ & $21(58.3)$ & $12(33.4)$ \\
1 week & $5(13.9)$ & $19(52.8)$ & $12(33.3)$ \\
2 weeks & $11(30.5)$ & $14(38.9)$ & $11(30.6)$ \\
\hline
\end{tabular}

ICCIDD/WHO: International Council for Control of lodine Deficiency Disorders/World Health Organization criteria: urinary iodine excretion $<10 \mu \mathrm{g} / \mathrm{dL}$ indicates "Deficiency" in the iodine nutrition state; between 10-29.9 $\mathrm{gg} / \mathrm{dL}$ denotes "Sufficiency"; and urinary iodine levels $\geq 30$ $\mu \mathrm{g} / \mathrm{dL}$ represents an "Excessive" intake. LID, low-iodine diet. RD, regular diet. ${ }^{*} p<0.05$ when compared to baseline (ANOVA).
A

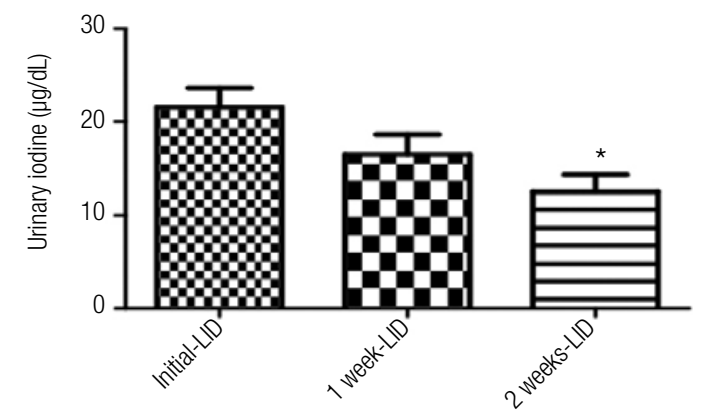

B

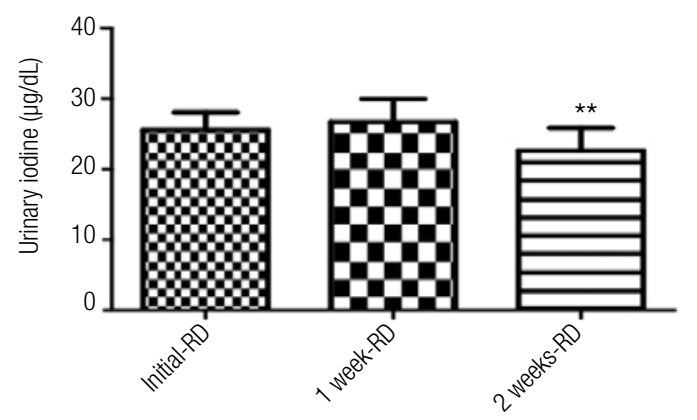

Figure 1. Effect of low-iodine diet in the urinary iodine excretion. LID, low-iodine diet (A). RD, regular diet (B). ${ }^{*} p<0.05$ if compared to baseline. ${ }^{* *}$ Not significant in the comparison with baseline and 1 week. 
Table 3. Effect of low-iodine diet in the proportion of cure after radioiodine

\begin{tabular}{lccc}
\hline & LID (N = 30)* & RD (N = 35) & p \\
\hline Cured: Not-cured (1 ${ }^{\text {st }}$ month) & $9: 21$ & $10: 25$ & 1.0 \\
Cured: Not-cured (2 ${ }^{\text {nd }}$ month) & $18: 12$ & $19: 16$ & 0.8 \\
Cured: Not-cured (3 $3^{\text {rd }}$ month) & $24: 6$ & $29: 6$ & 1.0 \\
Cured: Not-cured (6 $6^{\text {th }}$ month) & $26: 4$ & $29: 6$ & 0.74 \\
\hline
\end{tabular}

LID: low-iodine diet. RD: regular diet. N: number of patients. Comparisons using Fisher's exact test. One patient in each group was excluded due to missing follow-up at 6 month.

$6^{\text {th }}$ months after ${ }^{131} \mathrm{I}$, respectively; while $10,10,8$ and 6 patients were in euthyroidism at that times. In this analysis, one patient in each group was excluded due to loss of follow-up. At six month, only one patient from each group was on antithyroid drug treatment.

We also evaluated whether urinary iodine levels at the time of treatment, regardless of whether the patients adhered to a restrictive diet, affected the response to radioiodine. We regrouped the patients according to their urinary iodine levels indicative of deficient, sufficient or excessive iodine intake and determined whether their hyperthyroidism was controlled. As presented in table 4 , there were no differences among these 3 groups with regard to clinical or laboratory parameters, with the exception of urinary iodine. Among these 3 groups, the proportion of cured patients did not differ after 6 months of follow-up (Table 4). In fact, approximately $80 \%$ of the patients achieved a cure 3 months after ${ }^{131}$ I treatment; this percentage was maintained throughout the 6-month follow-up.

\section{DISCUSSION}

In the present study, we demonstrated that although a LID efficiently decreased urinary iodine excretion, this reduction did not affect the therapeutic response to ${ }^{131} \mathrm{I}$. The results indicated that even at urinary iodine levels compatible with sufficient or slightly excessive endoge- nous iodine, there was no reduction in the cure rate for hyperthyroidism compared with patients with a clear iodine deficiency who received ${ }^{131} \mathrm{I}$.

A LID is routinely prescribed before RAIT, especially in patients with DTC $(18,23-25)$. Such a diet reduces the endogenous pool of iodine, thereby contributing to the increased uptake and half-life of ${ }^{131} \mathrm{I}$ in the thyroid remnant. This enhanced uptake might result from increased NIS gene expression, a higher specific activity of ${ }^{131} \mathrm{I}$ or the increased sensitivity of the remaining thyroid tissue to TSH $(19,20)$. Despite the controversy regarding the appropriate degree and $\mathrm{du}^{-}$ ration of a LID $(26,27)$, the general recommendation is that patients should consume a LID, generally consisting of less than $50 \mu \mathrm{g}$ iodine/day, for 1 to 4 weeks $(18,22)$. This stringent diet results in a significant decrease in urinary iodine excretion, ranging from $50 \%$ to $80 \%$; more than $80 \%$ of the patients develop iodine deficiency. Consequently, this diet increases treatment effectiveness by more than $65 \%(27,28)$.

In the present study, urinary iodine excretion decreased by $23 \%$ in the first week and by more than $40 \%$ in the second week of a LID; this rate was lower than those reported in previous studies (29-31). Moreover, only $53 \%$ of the patients achieved iodine deficiency after a 2-week diet. However, previous reports (29-31) evaluated patients with DTC who underwent a thyroidectomy, which could explain this discrepancy because iodine clearance is faster in the absence of the thyroid. A recent study demonstrated that patients with DTC who underwent thyroid surgery and were subsequently exposed to iodine contrast exhibited normal urinary iodine levels 4 weeks after a LID (32). Another recent study reported that patients with an intact thyroid who underwent intravenous iodinated contrast procedures required approximately 75 days to achieve baseline urinary iodine levels (33).

Table 4. Baseline laboratory and clinical characteristics according to the degree of iodine nutritional intake and proportion of cure at $6^{\text {th }}$ month after radioiodine

\begin{tabular}{|c|c|c|c|c|}
\hline Parameters & Deficiency & Sufficiency & Excessive & p \\
\hline Gender (F:M) & $22: 4$ & $24: 2$ & $11: 2$ & NS \\
\hline Age & $46.5(16-72)$ & $43(23-76)$ & $42(24-53)$ & NS \\
\hline TSH (mUl/L) & $0.05(0.05-10.1)$ & $0.1(0.05-20.6)$ & $0.1(0.05-11)$ & NS \\
\hline FT4 (ng/dL) & $2.1(0.4-6.0)$ & $1.2(0.6-6.0)$ & $1.2(0.8-3.1)$ & NS \\
\hline Urinary iodine ( $\mu \mathrm{g} / \mathrm{dL})$ & $5.5(0.8-9.7)$ & $17.3(10.3-29.5)$ & $40.7(32-68.7)$ & $<0.05$ \\
\hline Thyroid volume (mL) & $30.6(8.1-189.8)$ & $28.9(8.3-63.5)$ & $24.7(13.4-33.9)$ & NS \\
\hline Cured: Not-cured & $22: 4$ & $20: 5$ & $10: 3$ & NS \\
\hline
\end{tabular}


Recent guidelines for and reviews of the treatment of hyperthyroidism do not recommend a special diet before RAIT, except in cases where the patients have been exposed to excessive amounts of iodine via iodinated contrast or amiodarone $(1,3)$. However, no studies have convincingly demonstrated whether an adequate or slightly elevated iodine nutritional status has a negative impact on the treatment of hyperthyroidism. A single recent study compared the impact of an iodinerestrictive diet for 2 or 3 weeks on patients referred for investigation based on suppressed TSH levels associated with thyroid nodules and goiters (17). In this study, 2 and 3 weeks of a LID similarly decreased urinary iodine levels by $60 \%$, which was accompanied by an approximately $40 \%$ increase in ${ }^{131}$ I uptake by the thyroid. However, in that study, the outcome after RAIT was not evaluated. In our study, we do not analyze ${ }^{131} \mathrm{I}$ uptake only the impact of RD. In this respect, we showed that there was a smaller decline in urinary iodine after 2 weeks on a LID (43\%) compared with previous reports. Several factors might explain this difference in the percent urinary iodine decrease after a LID, such as distinct etiologies of thyroid diseases, patient compliance to the strict diet and differences in the basal nutritional status of the patients in the 2 studies. In the present report, we demonstrated that the efficacy of RAIT for GD was not compromised by the iodine nutritional status, even when patients presented with urinary iodine excretion compatible with mildly excessive iodine ingestion. The study has some limitations and the main one is a limited number of patients. These findings will need to be confirmed in a larger cohort.

In summary, our study revealed that the corporal iodine pool did not compromise the therapeutic response to ${ }^{131} \mathrm{I}$ in patients with GD; in fact, the majority of patients exhibited the criteria for being cured after 6 months of RAIT, regardless of the urinary iodine levels. Then, for the management of patients with GD, we recommend a less stringent diet for a shorter time, along with the determination of urinary iodine levels to exclude exogenous and extreme iodine contamination, which will likely be sufficient before undergoing RAIT.

Acknowledgments: we are grateful for Yeda Queiroga Confessor and Ângela Maria Faria for their administrative assistance and The Federal Agency of Support and Evaluation of Postgraduate Education (Coordenação de Aperfeiçoamento de Pessoal de Nível Superior - Capes) and the São Paulo Research Foundation (Fundação de Amparo à Pesquisa do Estado de São Paulo - Fapesp) for financial support.
Disclosure: no potential conflict of interest relevant to this article was reported.

\section{REFERENCES}

1. Bahn Chair RS, Burch HB, Cooper DS, Garber JR, Greenlee MC, Klein I, et al. Hyperthyroidism and other causes of thyrotoxicosis: management guidelines of the American Thyroid Association and American Association of Clinical Endocrinologists. Thyroid. 2011;21(6):593-646.

2. Franklyn JA, Boelaert K. Thyrotoxicosis. Lancet. 2012;379(9821):1155-66.

3. Maia AL, Scheffel RS, Meyer EL, Mazeto GM, Carvalho GA, Graf $\mathrm{H}$, et al.; Brazilian Society of Endocrinology and Metabolism. The Brazilian consensus for the diagnosis and treatment of hyperthyroidism: recommendations by the Thyroid Department of the Brazilian Society of Endocrinology and Metabolism. Arq Bras Endocrinol Metabol. 2013;57(3):205-32.

4. Ross DS. Radioiodine therapy for hyperthyroidism. New Engl J Med. 2011;364:542-50.

5. Tuttle RM, PatienceT, Budd S. Treatment with propylthiouracil before radioactive iodine therapy is associated with a higher treatment failure rate than therapy with radioactive iodine alone in Graves' disease. Thyroid. 1995;5(4):243-7.

6. Imseis RE, Vanmiddlesworth L, Massie JD, Bush AJ, Vanmiddlesworth NR. Pretreatment with propylthiouracil but not methimazole reduces the therapeutic efficacy of iodine-131 in hyperthyroidism. J Clin Endocrinol Metab. 1998;83(2):685-7.

7. Allahabadia A, Daykin J, Holder RL, Sheppard MC, Gough SC, Franklyn JA. Age and gender predict the outcome of treatment for Graves' hyperthyroidism. J Clin Endocrinol Metab. 2000;85(3):1038-42.

8. Alexander EK, Larsen PR. High dose of (131)I therapy for the treatment of hyperthyroidism caused by Graves' disease. J Clin Endocrinol Metab. 2002;87(3):1073-7.

9. LeslieWD, Ward L, Salamon EA, Ludwig S, Rowe RC, Cowden EA. A randomized comparison of radioiodine doses in Graves' hyperthyroidism. J Clin Endocrinol Metab. 2003;88(3):978-83.

10. Erem C, Kandemir N, Hacihasanoglu A, Ersöz HO, Ukinc K, Kocak M. Radioiodine treatment of hyperthyroidism: prognostic factors affecting outcome. Endocrine. 2004;25(1):55-60.

11. Boelaert K, Syed AA, Manji N, Sheppard MC, Holder RL, Gough $\mathrm{SC}$, et al. Prediction of cure and risk of hypothyroidism in patients receiving 131 l for hyperthyroidism. Clin Endocrinol (Oxf). 2009;70(1):129-38.

12. Bonnema SJ, Hegedüs L. Radioiodine therapy in benign thyroid diseases: effects, side effects, and factors affecting therapeutic outcome. Endocr Rev. 2012;33(6):920-80.

13. Ruchała M, Sowiński J, Dolata M, Junik R, Gembicki M, Skiba A. Radioiodine treatment of hyperthyroidism in patients with low thyroid uptake. Nucl Med Rev Cent East Eur. 2005;8(1):28-32.

14. Vej-Hansen A, Nygaard B. [lodine uptake and the effect of radioiodine treatment--status after the addition of iodine to salt]. Ugeskr Laeger. 2005;167(39):3684-7.

15. Baczyk M, Junik R, Ziemnicka K, Sowiński J. lodine prophylaxis intensification. Influence on radioiodine uptake and activity of 131 used in the treatment of hyperthyroid patients with Graves' disease. Nuklearmedizin. 2005;44(5):197-9.

16. Meller B, Haase A, Seyfarth M, Wenzel BE, Richter E, Baehre M. [Reduced radioiodine uptake at increased iodine intake and 1311induced release of "cold" iodine stored in the thyroid]. Nuklearmedizin. 2005;44(4):137-42.

17. Morsch EP, Vanacor R, Furlanetto TW, Schmid H. Two weeks of a low-iodine diet are equivalent to 3 weeks for lowering urinary 
iodine and increasing thyroid radioactive iodine uptake. Thyroid. $2011 ; 21(1): 61-7$.

18. Sawka AM, Ibrahim-Zada I, Galacgac P, Tsang RW, Brierley JD, Ezzat S, et al. Dietary iodine restriction in preparation for radioactive iodine treatment or scanning in well-differentiated thyroid cancer: a systematic review. Thyroid. 2010;20(10):1129-38.

19. Uyttersprot N, Pelgrims N, Carrasco N, Gervy C, Maenhaut C, Dumont JE, et al. Moderate doses of iodide in vivo inhibit cell proliferation and the expression of thyroperoxidase and $\mathrm{Na}+/ /$ - symporter mRNAs in dog thyroid. Mol Cell Endocrinol. 1997;131(2):195-203.

20. De La Vieja A, Dohan O, Levy O, Carrasco N. Molecular analysis of the sodium/iodide symporter: impact on thyroid and extrathyroid pathophysiology. Physiol Rev. 2000;80(3):1083-105.

21. Esteves RZ, Kasamatsu TS, Kunii IS, Furuzawa GK, Vieira JG, Maciel RM. [Development of a semi-automated method for measuring urinary iodine and its application in epidemiological studies in Brazilian schoolchildren]. Arq Bras Endocrinol Metabol. 2007;51(9):1477-84.

22. Sapienza MT, Endo IS, Campos Neto GC, Tavares MG, Marone MM. [Radioiodine therapy for differentiated thyroid carcinoma: methods used to increase the radiation absorbed dose]. Arq Bras Endocrinol Metabol. 2005;49(3):341-9.

23. Pacini F, Schlumberger $M$, Dralle $H$, Elisei $R$, Smit JW, Wiersinga W; European Thyroid Cancer Taskforce. European consensus for the management of patients with differentiated thyroid carcinoma of the follicular epithelium. Eur J Endocrinol. 2006;154(6):787803.

24. Luster M, Clarke SE, Dietlein M, Lassmann M, Lind P, Oyen WJ, et al.; European Association of Nuclear Medicine (EANM). Guidelines for radioiodine therapy of differentiated thyroid cancer. Eur J Nucl Med Mol Imaging. 2008;35(10):1941-59.

25. American Thyroid Association (ATA) Guidelines Taskforce on Thyroid Nodules and Differentiated Thyroid Cancer; Cooper DS,
Doherty GM, Haugen BR, Kloos RT, Lee SL, Mandel SJ, et al. Revised American Thyroid Association management guidelines for patients with thyroid nodules and differentiated thyroid cancer. Thyroid. 2009;19(11):1167-214.

26. Hinds SR 2nd, Stack AL, Stocker DJ. Low-iodine diet revisited: importance in nuclear medicine imaging and management. Clin Nucl Med. 2008;33(4):247-50.

27. Tomoda C, Uruno T, Takamura $Y$, Ito $Y$, Miya A, Kobayashi $K$, et al. Reevaluation of stringent low iodine diet in outpatient preparation for radioiodine examination and therapy. Endocr $\mathrm{J}$. 2005;52(2):237-40.

28. Pluijmen MJ, Eustatia-Rutten C, Goslings BM, Stokkel MP, Arias AM, Diamant M, et al. Effects of low-iodide diet on postsurgical radioiodide ablation therapy in patients with differentiated thyroid carcinoma. Clin Endocrinol (Oxf). 2003;58(4):428-35.

29. Lakshmanan M, Schaffer A, Robbins J, Reynolds J, Norton J. A simplified low iodine diet in l-131 scanning and therapy of thyroid cancer. Clin Nucl Med. 1988;13(12):866-8.

30. Park 2nd JT, Hennessey JV.Two-week low iodine diet is necessary for adequate outpatient preparation for radioiodine rhTSH scanning in patients taking levothyroxine. Thyroid. 2004;14(1):57-63.

31. Prestwich RJ, Gerrard GE. Low-iodine diet before radioiodine uptake scans or therapy - flawed advice to U.K. patients. Clin Oncol (R Coll Radiol). 2005;17(2):73-4.

32. Padovani RP, KasamatsuTS, Nakabashi CC, Camacho CP, Andreoni DM, Malouf EZ, et al. One month is sufficient for urinary iodine to return to its baseline value after the use of water-soluble iodinated contrast agents in post-thyroidectomy patients requiring radioiodine therapy. Thyroid. 2012;22(9):926-30.

33. Nimmons GL, Funk GF, Graham MM, Pagedar NA. Urinary iodine excretion after contrast computed tomography scan: implications for radioactive iodine use. JAMA Otolaryngol Head Neck Surg. 2013;139(5):479-82. 